\title{
Influência do uso de aditivo acelerador de resistência baseado em nitrato de cálcio no desempenho de argamassas de cimento Portland com adição de cinza volante
}

\author{
Influence of the use of accelerating admixture \\ based on calcium nitrate in the performance \\ of fly ash blended Portland cement mortars.
}

Felipe Lima $\operatorname{Costa}^{1}$, Iago Lopes dos $\operatorname{Santos}^{1}$, Laura Silvestro ${ }^{1}$ Erich David Rodríguez ${ }^{2}$, Ana Paula Kirchheim ${ }^{1}$

\footnotetext{
${ }^{1}$ Programa de Pós-Graduação em Engenharia Civil: Construção e Infraestrutura (PPGCI), Universidade Federal do Rio Grande do Sul (UFRGS), Porto Alegre, Rio Grande do Sul, Brasil.

${ }^{2}$ Departamento de Estruturas e Construção Civil. Engenharia Civil, Centro de Tecnologia, Universidade Federal de Santa Maria (UFSM), Santa Maria, Rio Grande do Sul, Brasil.

e-mail: felmcosta@gmail.com, iago.lopes.santos@gmail.com, laurasilvestro@ymail.com, anapaula.k@gmail.com, erich.rodriguez@ufsm.br
}

\section{RESUMO}

A construção civil tende a exigir a otimização dos processos, com prazos de entrega reduzidos. Logo, tornase necessária a busca por alternativas que forneçam as propriedades necessárias ao concreto em períodos de tempo mais curtos. O objetivo deste trabalho é avaliar a influência de um aditivo acelerador de resistência baseado em nitrato de cálcio na resistência à compressão e em propriedades físicas de argamassas de cimento Portland, com diferentes teores de cinza volante (CV), visando analisar se a incorporação do aditivo compensaria a baixa contribuição desta adição nas resistências nas primeiras idades. Foram realizados ensaios de calorimetria isotérmica, absorção de água por capilaridade, índice de consistência e resistência à compressão em misturas com teores de aditivo de $0 \%, 0,33 \%, 0,66 \%$ e $1,00 \%$. No que se refere ao tempo de pega final, nas amostras sem CV, o aditivo reduziu este período. Nas amostras com $40 \%$ e $60 \%$ de CV, verificou-se um aumento deste tempo. Para as resistências à compressão de 1 dia, o teor de aditivo que gerou os maiores valores foi de 1,00\% para as argamassas com $0 \%$ e $40 \% \mathrm{CV}$, não existindo diferenças estatisticamente significativas para os sistemas com $60 \%$. Já em idades superiores, o aditivo ocasionou reduções na resistência das amostras sem CV e aumentos proporcionais ao teor de aditivo nas amostras com $40 \%$ e $60 \%$ de CV. Constatou-se que as argamassas com aditivo e sem adição de CV apresentaram uma redução no índice de absorção por capilaridade. Já para as amostras com $40 \%$ e $60 \%$ de CV os menores índices de absorção foram obtidos nos traços sem aditivo. Portanto, é possível concluir que o aditivo avaliado nesta pesquisa acelerou as reações de hidratação, gerando um aumento nas resistências em idades iniciais, mas com um acréscimo insuficiente para compensar a queda de resistência pela incorporação de CV na composição das amostras. Levando em consideração as diferentes propriedades avaliadas, observou-se não ser possível estabelecer um teor ótimo de aditivo para cada teor de CV estabelecido. Sendo necessário avaliar qual propriedade é de maior interesse ao usuário.

Palavras-chave: Nitrato de cálcio, acelerador de resistência, cimento, cinza volante, hidratação

\section{ABSTRACT}

Civil construction tends to require the optimization of processes with reduced times. Therefore, it is necessary to search for alternatives that provide the required properties to the concrete, in shorter periods of time. The objective of this work is to evaluate the influence of a calcium nitrate based accelerator admixture on the properties of Portland cement mortars with different fly ash (FA) contents, in order to analyze the effect in the incorporation of the admixture, mainly if the accelerator is able to compensate the low strength contribution of the FA at early ages. Tests were carried out using isothermal calorimetry, water absorption by capillarity, consistency index and compressive strength in mixtures with admixture contents of $0 \%, 0,33 \%, 0,66 \%$ 
and $1,00 \%$. Regarding setting time results, as excepted the admixture accelerated the final setting time. By the other hand, in the samples with $40 \%$ and $60 \%$ of FA, an increase of the final setting time was verified. For the 1-day compressive strengths, the admixture content that have generated the highest values was $1.00 \%$ for mortars with $0 \%$ and $40 \%$ FA. At higher ages, the admixtures led to reduce the compressive strength values of the samples without FA. On the other hand, in the samples with $40 \%$ and $60 \%$ of FA with the use of the accelerator higher compressive strength were identified. It was verified that the mortars with admixture and without addition of FA showed a reduction in the absorption index by capillarity. For the samples with $40 \%$ and $60 \%$ of FA, the lower absorption index was obtained in the samples without admixture. Therefore, it is possible to conclude that the admixture evaluated in this research accelerated the hydration reactions, generating an increase in the compressive strength at early ages, but with an insufficient increase to compensate the lower reactivity of the FA. Taking into account the different properties evaluated, it was not possible to establish an optimum admixture content for each FA content. It is necessary to evaluate which property is of greater interest to the user.

Keywords: Calcium nitrate, accelerating admixture, cement, fly ash, hydration

\section{INTRODUÇÃO}

A indústria da construção, influenciada pela elevada competitividade do setor, exige das empresas um rigoroso planejamento e controle das obras, impactando em uma melhoria na qualidade e otimização de custos e prazos. Neste sentido, a utilização de aditivos aceleradores de resistência na produção de concretos contribui com o melhoramento do desempenho nas primeiras idades e posterior otimização nos tempos ou processos construtivos. Concretos com elevadas resistências iniciais (com valores de resistência à compressão próximos de $35 \mathrm{MPa}$ em 1 dia [1]) ou com reduzidos tempos de pega permitem reduzir custos operacionais e aumentam a capacidade de produção. A norma brasileira, NBR 11768:2011 [2], classifica estes aditivos em dois grupos, considerando que o primeiro tipo citado é responsável por um aumento da taxa de desenvolvimento das resistências inicias, podendo ocasionar reduções no tempo de pega. Já o segundo grupo, constituído pelos aditivos aceleradores de pega, é caracterizado por reduzir o período de transição do estado plástico para ao estado endurecido. A ASTM C-494 [3] classifica ambos na categoria de aditivos aceleradores, com a função de acelerar tanto o tempo de pega como o desenvolvimento de resistências iniciais no concreto.

Os aditivos aceleradores alteram a taxa de hidratação do cimento por mecanismos diversos, cuja forma de ação ainda está sendo avaliada com mais detalhe [4]. EDMEADES E HEWLETT [5] descrevem que os aceleradores de pega afetam principalmente a fase aluminato tricálcico $\left(\mathrm{Ca}_{3} \mathrm{Al}_{2} \mathrm{O}_{6}\right.$ ou mais conhecido na química do cimento ${ }^{1}$ como $\mathrm{C}_{3} \mathrm{~A}$ ) do cimento Portland. Estes são geralmente álcalis que promovem a dissolução da sílica e da alumina, influenciando também na taxa de hidratação da alita $\left(\mathrm{Ca}_{3} \mathrm{SiO}_{5}\right.$ ou $\left.\mathrm{C}_{3} \mathrm{~S}\right)$ no cimento Portland [6], resultando no aumento da liberação de calor e formação do gel C-S-H nas idades iniciais. Todavia, AÏTCIN [7] ressalta que a hidratação acelerada da alita pode ter efeitos negativos, tais como a diminuição da resistência à compressão a longo prazo, assim como o aumento do calor de hidratação que pode gerar fissuras e influenciar na sua durabilidade.

Este tipo de aditivo é amplamente utilizado em concretos para a fabricação/produção de pavimentos, elementos pré-moldados, serviços urgentes de reparo, além do lançamento em temperaturas baixas $\left(2\right.$ a $4{ }^{\circ} \mathrm{C}$, por exemplo), diminuindo o risco de congelamento[8]. MEHTA E MONTEIRO [9] ainda destacam que, no contexto da construção, estes aditivos possibilitam a antecipação das operações de acabamento, redução no tempo de proteção e cura da estrutura, bem como a diminuição no tempo de uso das fôrmas. RIXOM [10] relata uma redução de até $33 \%$ nos custos de mão de obra devido à utilização de aditivos aceleradores de pega em regiões de clima frio.

Nesse contexto, o cloreto de cálcio já foi um dos aditivos mais utilizados como acelerador de pega e de resistência inicial no cimento Portland, devido ao baixo custo e maior eficiência quando comparado a outros tipos de aditivos que compõe o grupo de aceleradores [7]. No entanto, tem aplicação limitada devido à presença de íons cloreto em sua composição, que podem provocar corrosão nas armaduras [11].

Outros aditivos aceleradores isentos de íons cloreto encontram-se disponíveis. Os mais abordados na literatura são o formiato de cálcio e a trietanolamina [5] [8] [12], além destes, é possível citar o nitrato de cálcio (NC) [8] [13], que também atua como um eficiente aditivo inibidor de corrosão. NEVILLE [8] salienta que o formiato de cálcio possui baixa solubilidade em água e somente é eficiente quando utilizado com cimentos que possuem um baixo teor de $\mathrm{SO}_{3}$ e uma relação $\mathrm{C}_{3} \mathrm{~A} / \mathrm{SO}_{3}$ igual ou maior que 4 . Também é importante destacar que a trietanolamina pode atuar como aditivo acelerador ou retardador em função do tipo de

\footnotetext{
${ }^{1}$ Onde $\mathrm{C}=\mathrm{CaO} ; \mathrm{S}=\mathrm{SiO}_{2} ; \mathrm{A}=\mathrm{Al}_{2} \mathrm{O}_{3} ;$ e $\mathrm{H}=\mathrm{H}_{2} \mathrm{O}$
} 
cimento e taxa de adição [14].

Os quatro tipos de aditivos aceleradores reconhecidos pelo "AMERICAN CONCRETE INSTITUTE" (ACI) através do "Manual of Concrete Practice" [15], correspondem a:

- Sais inorgânicos: Cloretos, brometos, fluoretos, carbonatos, tiocianatos, nitritos, tiossulfatos, silicatos, aluminatos e hidróxidos alcalinos;

- Compostos orgânicos solúveis: Trietanolamina (TEA), formiato de cálcio, acetato de cálcio, propionato de cálcio e butirato de cálcio.

Além destes, também são diferenciados os aditivos aceleradores de pega dos aceleradores de resistência:

- Aceleradores de pega: Silicato de sódio, aluminato de sódio, cloreto de alumínio, fluoreto de sódio, e cloreto de cálcio;

- Aceleradores de resistência: Aluminato de cálcio, carbonato de magnésio finamente dividido, silicatos e carbonato de cálcio.

Estes aceleradores podem ser utilizados sem restrições com aditivos redutores de água e superplastificantes. Entretanto, o desempenho de tais aditivos, assim como as resistências mecânicas iniciais atingidas pelos materiais, são inferiores quando comparado ao obtido pelo cloreto de cálcio [7].

Face à problemática utilização do cloreto de cálcio no que diz respeito à corrosão das armaduras, se faz necessária a busca por aditivos isentos de cloretos, mas ainda com um baixo custo. Nesse contexto, o nitrato de cálcio se mostra como uma solução satisfatória. MEAGHER et al. [11] encontrou resistências à compressão $20 \%$ superiores nas amostras com aditivos à base de NC, após 12 h da mistura, quando comparados com as amostras com cloreto de cálcio, ambas compostas por cimento Portland do tipo I, sem a utilização de adições. Diversos autores expõem a mutifuncionalidade do NC frente às propriedades do concreto. AGGOUN et al. [13], observou um aumento de 50\% nas resistências das idades de 1 e 3 dias, com uma diminuição de $20 \%$ nos tempos de pega das amostras. Esses resultados foram semelhantes em outros trabalhos, no entanto, ambos ressaltam que a eficiência do aditivo depende do tipo de cimento e, aparentemente, do conteúdo de belita $\left(\mathrm{Ca}_{2} \mathrm{SiO}_{4}\right.$ ou $\left.\mathrm{C}_{2} \mathrm{~S}\right)$ [16]. JUSTNES e PETERSEN [17] demonstram que o NC pode neutralizar os efeitos retardantes provocados por plastificantes, preservando, ainda, sua reologia. KARAGÖL et al. [18] também constata efeitos positivos quanto a uso do aditivo como um anticongelante em concretos submetidos à baixas temperaturas. NEVILLE [8], AGGOUN et al. [13] e JUSTNES [19] ressaltam ainda as propriedades inibidoras da corrosão por cloretos do NC.

Este trabalho aborda a avaliação da influência de um aditivo acelerador de resistência inicial à base de nitrato de cálcio (NC) nas propriedades de argamassas de cimento Portland preparadas com diferentes teores de cinza volante $(\mathrm{CV})$. Levando em consideração, também, seus possíveis efeitos quanto à cinética de hidratação, tempo de pega, absorção de água por capilaridade e resistência à compressão final. Optou-se pela utilização de diversos teores de CV como substituição ao cimento visando analisar se a incorporação do NC como aditivo acelerador de resistência inicial poderia mitigar a baixa contribuição deste tipo de adição pozolânica nas resistências das argamassas nas primeiras idades.

A cinza volante melhora a durabilidade das estruturas devido ao consumo de hidróxido de cálcio $\left(\mathrm{Ca}(\mathrm{OH})_{2}\right.$ ou portlandita) e ao refinamento dos poros [9], e posterior formação em idades avançadas $(>90$ dias) de silicatos cálcicos hidratados $(\mathrm{C}-\mathrm{S}-\mathrm{H})$ adicionais, responsáveis pela resistência mecânica do cimento Portland [20]. Concretos com CV possuem uma melhor trabalhabilidade em estado fresco. Todavia, as resistências iniciais são menores devido ao menor conteúdo de clínquer e às reações tardias do material pozolânico, o que limita a proporção de CV que pode ser incorporada ao cimento, além de restringir sua utilização em obras onde altos valores de resistência à compressão nas primeiras idades do concreto são desejados [14].

\section{MATERIAIS E MÉTODOS}

\subsection{Materiais}

Foi utilizado o cimento Portland CP V-ARI, de acordo com a NBR 5733:1991[21], com substituição em massa de cinza volante em diversos teores. A composição química da cinza volante e do cimento e as principais características físicas destes materiais estão apresentadas nas Tabelas 1 a 3 . As caracterizações química e física do cimento foram fornecidas pelo fabricante. Já a composição química da cinza volante foi determinada por fluorescência de raio-X (FRX), realizada com o aparelho da marca SHIMADZU, modelo XRF-1800. 
Sua superfície específica foi determinada pelo método de adsorção multimolecular de Brunauer Emmett Teller (BET) usando a Quantachrome Nova 1000, onde a amostra foi previamente aquecida a $300{ }^{\circ} \mathrm{C}$ no vácuo, durante um período de 3 horas. Para a determinação da massa específica foi seguido o preconizado pela NBR NM 23:2001 [22]. A análise de distribuição do tamanho de partícula da CV foi realizada por difração a laser em um equipamento CILAS Particle Size Analyser, modelo CILAS 1180 Liquid usando água como material dispersante e aplicando ultrassom de $38 \mathrm{kHz}$ por $60 \mathrm{~s}$.

Tabela 1: Composição química do cimento Portland CP-V ARI e da cinza volante

\begin{tabular}{|c|c|c|c|c|c|c|c|}
\hline \multicolumn{4}{|c|}{ Cimento Portland } & \multicolumn{4}{|c|}{ Cinza Volante } \\
\hline Óxidos & $(\%)$ & Óxidos & $(\%)$ & Óxidos & $(\%)$ & Óxidos & $(\%)$ \\
\hline $\mathrm{SiO} 2$ & 17,87 & $\mathrm{ZrO} 2$ & 0,00 & $\mathrm{SiO} 2$ & 60,90 & $\mathrm{ZrO} 2$ & 0,10 \\
\hline $\mathrm{Al} 2 \mathrm{O} 3$ & 2,87 & $\mathrm{ZnO}$ & 0,00 & $\mathrm{~A} 12 \mathrm{O} 3$ & 18,50 & $\mathrm{ZnO}$ & 0,07 \\
\hline $\mathrm{Fe} 2 \mathrm{O} 3$ & 5,02 & $\mathrm{Cr} 2 \mathrm{O} 3$ & 0,00 & $\mathrm{Fe} 2 \mathrm{O} 3$ & 7,30 & $\mathrm{Cr} 2 \mathrm{O} 3$ & 0,05 \\
\hline K2O & 0,89 & $\mathrm{MnO}$ & 0,15 & K2O & 3,65 & $\mathrm{MnO}$ & 0,04 \\
\hline $\mathrm{CaO}$ & 62,25 & $\mathrm{SrO}$ & 0,32 & $\mathrm{CaO}$ & 3,45 & $\mathrm{SrO}$ & 0,03 \\
\hline $\mathrm{TiO} 2$ & 0,00 & $\mathrm{Co} 2 \mathrm{O} 3$ & 0,00 & $\mathrm{TiO} 2$ & 1,78 & $\mathrm{Co} 2 \mathrm{O} 3$ & 0,02 \\
\hline $\mathrm{SO}_{3}$ & 4,06 & $\mathrm{Rb} 2 \mathrm{O}$ & 0,00 & $\mathrm{SO}_{3}$ & 0,90 & $\mathrm{Rb} 2 \mathrm{O}$ & 0,02 \\
\hline $\mathrm{MgO}$ & 0,00 & $\mathrm{NiO}$ & 0,02 & $\mathrm{MgO}$ & 0,50 & $\mathrm{NiO}$ & 0,02 \\
\hline $\mathrm{Na}_{2} \mathrm{O}$ & 0,15 & $\mathrm{Y} 2 \mathrm{O} 3$ & 0,00 & $\mathrm{Na}_{2} \mathrm{O}$ & 0,17 & $\mathrm{Y} 2 \mathrm{O} 3$ & 0,02 \\
\hline $\mathrm{BaO}$ & 0,00 & $\mathrm{Cl}$ & 0,25 & $\mathrm{BaO}$ & 0,12 & $\mathrm{Cl}$ & 0,00 \\
\hline $\mathrm{P} 2 \mathrm{O} 5$ & 0,25 & $\mathrm{CO}_{2}$ & 5,90 & $\mathrm{P} 2 \mathrm{O} 5$ & 0,11 & $\mathrm{CO}_{2}$ & 2,25 \\
\hline
\end{tabular}

Tabela 2: Caracterização física do cimento Portland CP-V ARI

\begin{tabular}{lcc}
\hline \multicolumn{3}{c}{ Cimento Portland } \\
\hline Perda de massa ao fogo $\left(1000{ }^{\circ} \mathrm{C}\right)$ & $5,90 \%$ & NBR NM 18:2012 [23] \\
\hline Massa específica & $3.040 \mathrm{~kg} / \mathrm{m}^{3}$ & NBR NM 23:2001 [22] \\
\hline Finura Blaine & $4.750 \mathrm{~m}^{2} / \mathrm{kg}$ & NBR 16372:2015 [24] \\
\hline $\begin{array}{l}\text { Porcentagem de material retido na peneira } \\
\# 200\end{array}$ & $0,12 \%$ & \\
\hline Expansibilidade & $0,0 \mathrm{~mm}$ & NBR 11582:2016 [25] \\
\hline Início de pega & $165 \mathrm{~min}$ & NBR NM 65:2003 [26] \\
\hline Final de pega & $215 \mathrm{~min}$ & NBR NM 65:2003 [26] \\
\hline Resistência à compressão 1 dia & $28,3 \mathrm{MPa}$ & NBR 7215:1997 [27] \\
\hline Resistência à compressão 3 dias & $45,8 \mathrm{MPa}$ & NBR 7215:1997 [27] \\
\hline Resistência à compressão 7 dias & $49,3 \mathrm{MPa}$ & NBR 7215:1997 [27] \\
\hline Resistência à compressão 28 dias & $57,7 \mathrm{MPa}$ & NBR 7215:1997 [27] \\
\hline
\end{tabular}

Tabela 3: Caracterização física da cinza volante

\begin{tabular}{lc}
\hline \multicolumn{2}{c}{ Cinza Volante } \\
\hline Perda de massa ao fogo $\left(1000^{\circ} \mathrm{C}\right)$ & $2,25 \%$ \\
\hline Massa específica & $2.080 \mathrm{~kg} / \mathrm{m}^{3}$ \\
\hline Superfície específica (BET) & $2.690 \mathrm{~m}^{2} / \mathrm{kg}$ \\
\hline $\begin{array}{l}\text { Tamanho médio de partícula obtido por granulometria } \\
\text { laser - D médio }\end{array}$ & $24,06 \mu \mathrm{m}$ \\
\hline D10 & $1,31 \mu \mathrm{m}$ \\
\hline D50 & $18,33 \mu \mathrm{m}$ \\
\hline D90 & $56,55 \mu \mathrm{m}$ \\
\hline
\end{tabular}


Como agregado miúdo, foi utilizada uma areia quartzosa padronizada pela NBR 7214:2015 [28], com módulo de finura de 2,5 [29], massa específica de $2.400 \mathrm{~kg} / \mathrm{m}^{3}$ [30], massa unitária de $1.730 \mathrm{~kg} / \mathrm{m}^{3}$ [31] e absorção de água de 0,29\% [32].

$\mathrm{O}$ aditivo acelerador de resistência inicial utilizado, com base química de nitrato de cálcio, possui densidade de $1,01 \mathrm{~g} / \mathrm{cm}^{3}$. Para a dosagem do mesmo, o fabricante recomenda teores dentro do intervalo de $0,2 \%$ a $1,0 \%$ em relação a massa de cimento.

\subsection{Avaliação da cinética de hidratação}

Foram produzidas pastas com cimento CP V - ARI, relação a/c de 0,48 (as pastas foram preparadas com a mesma relação a/c estabelecida pela NBR 7215:1997) [27], norma que foi utilizada para avaliar a resistência à compressão dos corpos de prova de argamassa moldados neste trabalho), teores de substituição de cinza volante em relação à massa de cimento de $0 \%, 40 \%$ e $60 \%$ e teores de aditivo acelerador de resistência inicial de $0,00 \%, 0,33 \%, 0,66 \%$ e $1,00 \%$ em relação à massa total de aglomerante, dentro do intervalo recomendado pelo fabricante do produto. Na Tabela 4 são apresentadas as misturas analisadas na pesquisa, bem como a designação adotada a fim de identificação de cada um dos traços analisados.

Tabela 4: Designação das configurações analisadas

\begin{tabular}{|c|c|}
\hline Designação & Configuração \\
\hline \multirow{2}{*}{ CV0_AD0 } & $0 \%$ de cinza volante \\
\hline & $0 \%$ de aditivo acelerador de resistência inicial \\
\hline \multirow{2}{*}{ CV40_AD0 } & $40 \%$ de cinza volante \\
\hline & $0 \%$ de aditivo acelerador de resistência inicial \\
\hline \multirow{2}{*}{ CV60_AD0 } & $60 \%$ de cinza volante \\
\hline & $0 \%$ de aditivo acelerador de resistência inicial \\
\hline \multirow{2}{*}{ CV0_AD33 } & $0 \%$ de cinza volante \\
\hline & $0,33 \%$ de aditivo acelerador de resistência inicial \\
\hline \multirow{2}{*}{ CV40_AD33 } & $40 \%$ de cinza volante \\
\hline & $0,33 \%$ de aditivo acelerador de resistência inicial \\
\hline \multirow{2}{*}{ CV60_AD33 } & $60 \%$ de cinza volante \\
\hline & $0,33 \%$ de aditivo acelerador de resistência inicial \\
\hline \multirow{2}{*}{ CV0_AD66 } & $0 \%$ de cinza volante \\
\hline & $0,66 \%$ de aditivo acelerador de resistência inicial \\
\hline \multirow{2}{*}{ CV40_AD66 } & $40 \%$ de cinza volante \\
\hline & $0,66 \%$ de aditivo acelerador de resistência inicial \\
\hline \multirow{2}{*}{ CV60_AD66 } & $60 \%$ de cinza volante \\
\hline & $0,66 \%$ de aditivo acelerador de resistência inicial \\
\hline \multirow{2}{*}{ CV0_AD100 } & $0 \%$ de cinza volante \\
\hline & $1 \%$ de aditivo acelerador de resistência inicial \\
\hline \multirow{2}{*}{ CV40_AD100 } & $40 \%$ de cinza volante \\
\hline & $1 \%$ de aditivo acelerador de resistência inicial \\
\hline \multirow{2}{*}{ CV60_AD100 } & $60 \%$ de cinza volante \\
\hline & $1 \%$ de aditivo acelerador de resistência inicial \\
\hline
\end{tabular}

A cinética do processo de hidratação do cimento Portland foi avaliada por calorimetria de condução isotérmica, em um micro-calorímetro (TAM Air - TA Instruments) com sensibilidade de $20 \mu \mathrm{W}$. Todas as amostras de pasta de cimento analisadas possuíam massa total de 3,7 g. Para os traços com cimento e cinza volante, os materiais em pó foram previamente homogeneizados durante 1 minuto. Posteriormente, foi adicionada água e, após mistura externa manual por um período de 2 minutos, as amostras foram colocadas no calorímetro. A liberação de calor foi registrada durante 72 horas, a uma temperatura de $25^{\circ} \mathrm{C}$. 


\subsection{Avaliação de resistência e desempenho}

Foram preparadas argamassas com as mesmas configurações das pastas em relação aos teores de substituição de cinza volante e aditivo acelerador de resistência inicial (Tabela 5), com relação a/c de 0,48 e proporção aglomerante: areia de 1:3. Também avaliou-se o índice de consistência normal (com base na NBR 7215:1997 [27]), objetivando identificar a influência dos teores de cinza volante e de aditivo acelerador de resistência inicial na consistência das argamassas. A fim de analisar a resistência à compressão, corpos de prova cilíndricos de $50 \times 100 \mathrm{~mm}$ foram rompidos nas idades de 1, 3, 7 e 28 dias, conforme NBR 7215:1997 [27]. Empregou-se o método de cura úmida (UR> $95 \%$ e $23 \pm 2^{\circ} \mathrm{C}$ ). Utilizou-se um equipamento marca EMIC, modelo DL 20000, com velocidade de aplicação de carga de 0,25 $\pm 0,05 \mathrm{MPa} / \mathrm{s}$. Também realizou-se o ensaio de absorção de água por capilaridade nos corpos de prova com 28 dias, de acordo com a NBR 9779:2012 [33].

\section{RESULTADOS E DISCUSSÃO}

\subsection{Avaliação da cinética de hidratação}

Nos primeiros minutos (< 10 min) identifica-se um pico de liberação de calor que é atribuído a dissolução das fases mais reativas do clínquer $\left(\mathrm{C}_{3} \mathrm{~A}\right.$ e $\left.\mathrm{C}_{3} \mathrm{~S}\right)$ onde os sistemas sem incorporação de aditivos reportaram um valor máximo de aproximadamente $\sim 50 \mathrm{~mW} / \mathrm{g}$, independentemente do conteúdo de CV (Figura 1A). Os sistemas com um teor de $0,33 \%$ de aditivo (Figura 1B) apresentaram um pico máximo de liberação de calor até $40 \%$ maior frente aos sistemas de referência sem aditivo. Já nas amostras com $0,66 \%$ e 1,00\% de teor de aditivo, o nitrato de cálcio aparenta não influenciar de maneira significativa o pico de liberação de calor inicial, com exceção da amostra CV60_AD100, que obteve valores mais elevados (aproximadamente 14\% maiores). O resultado indica um aumento do calor de hidratação, o que pode ser prejudicial na concretagem de grandes volumes de concreto [34], mas que, por outro lado, pode ser útil em situações de ambientes frios.
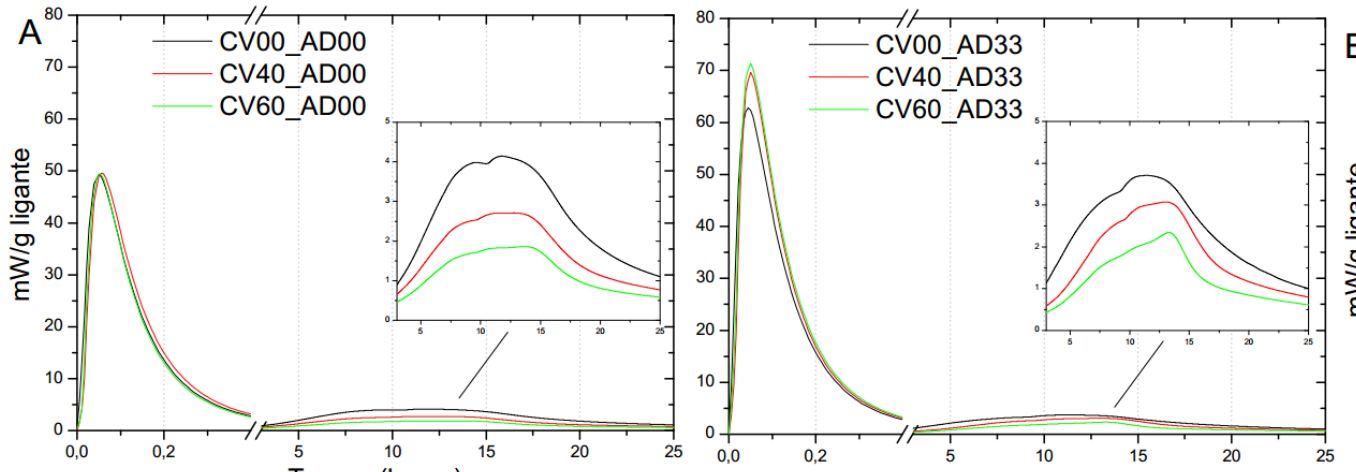

B
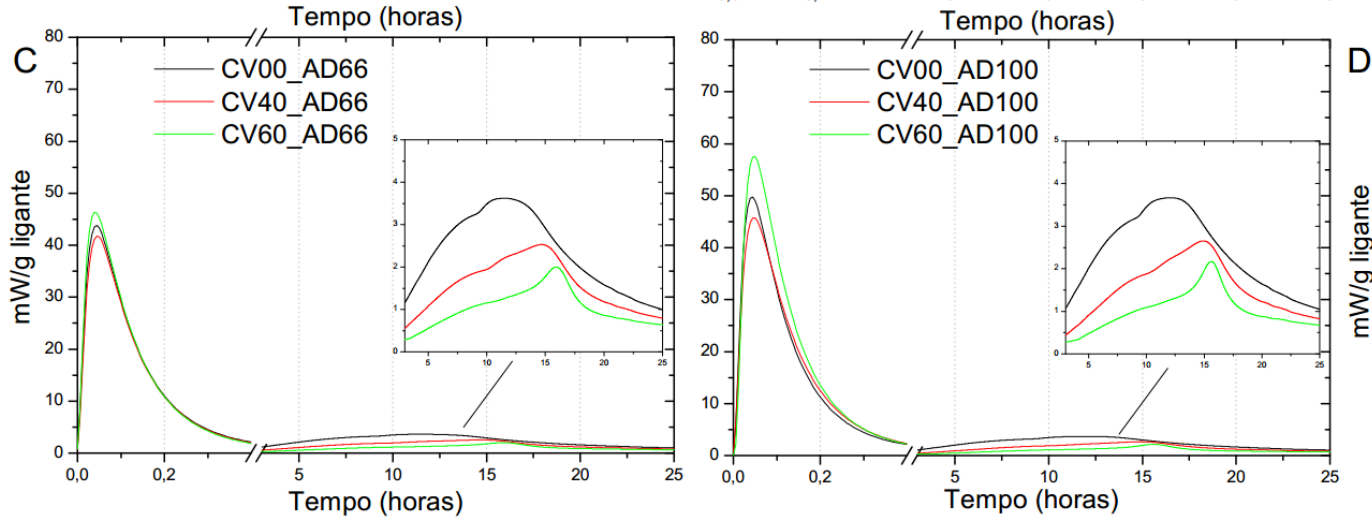

Figura 1: Fluxo de calor das amostras durante as primeiras 25 horas de hidratação. Sistemas com incorporação de aditivo nas proporções de: A. $0,00 \%$; B. $0,33 \%$; C. $0,66 \%$ e D. $1,00 \%$.

O segundo pico de liberação de calor ocorre logo após a etapa de dissolução lenta (> 5 h) ou período de dormência, onde as reações químicas desaceleram e ocorre o acúmulo de cálcio no sistema, o qual é originado a partir da dissolução do $\mathrm{C}_{3} \mathrm{~S}$ durante o período de reação inicial. $\mathrm{O}$ excesso de cálcio passa a ser consumido através da nucleação e crescimento de fases tipo C-S-H na alita e também em suas imediações, dando origem ao período de aceleração, caracterizado por uma nova emissão de calor [35]. Como esperado, a incor- 
poração de CV diminui o valor máximo do segundo pico de liberação de calor como consequência ao menor conteúdo de clínquer. Porém, a inclusão do aditivo não interferiu de maneira significativa nos valores máximos de emissão de calor do segundo pico. Todavia, houve uma mudança significativa em sua morfologia, com um deslocamento do valor máximo para maiores tempos de hidratação, como observado nas amostras com $0,33 \%, 0,66 \%$ e $1,00 \%$ de teor de aditivo. Tal resultado diverge do encontrado por OEY et al. [36], onde o segundo pico ocorreu mais rapidamente. Todavia, os resultados coincidem com o reportado por NOCUNWCZELIK [37], onde a concentração dos íons na fase líquida, durante a hidratação do cimento, modifica a cinética de formação dos produtos, assim como o calor liberado. A presença do nitrato altera as características e formação das fases de monosulfoaluminato (AFm) durante a hidratação do cimento (especificamente da fase de aluminato tricálcico). Da mesma maneira, os componentes de nitrato são ligados na pasta de cimento e dependem diretamente do conteúdo de alumínio no sistema e da temperatura [37].

O calor total liberado (Figura 2), após $72 \mathrm{~h}$ de hidratação, registrou diminuição devido ao incremento do conteúdo de CV, onde o CV00_AD00 registrou um valor de 324 J/g e a pasta CV60_AD00 um valor de $169 \mathrm{~J} / \mathrm{g}$. Em termos gerais, e independentemente do conteúdo de aditivo, as amostras com menor teor de cinza volante apresentaram os maiores valores de calor acumulado (aproximadamente $40 \%$ superior, com relação às pastas com $40 \%$ de CV e $80 \%$ superior com relação às pastas com 60\% de CV), este resultado já era esperado uma vez que as reações pozolânicas acontecem mais lentamente, no decorrer de dias e não de horas, devido à necessidade da formação do $\mathrm{Ca}(\mathrm{OH})_{2}$. Todavia, nas amostras com $40 \%$ e $60 \%$ de $\mathrm{CV}$, com concentração de $0,33 \%$ de aditivo apresentaram um aumento de $5 \%$ e $9 \%$, respectivamente, na quantidade de calor acumulado em relação às amostras sem adição de aditivo, enquanto que aquelas que possuíam a concentração de $0,66 \%$ e $1 \%$ apresentaram uma redução de cerca de $8 \%$, como demostrado na Figura 2.
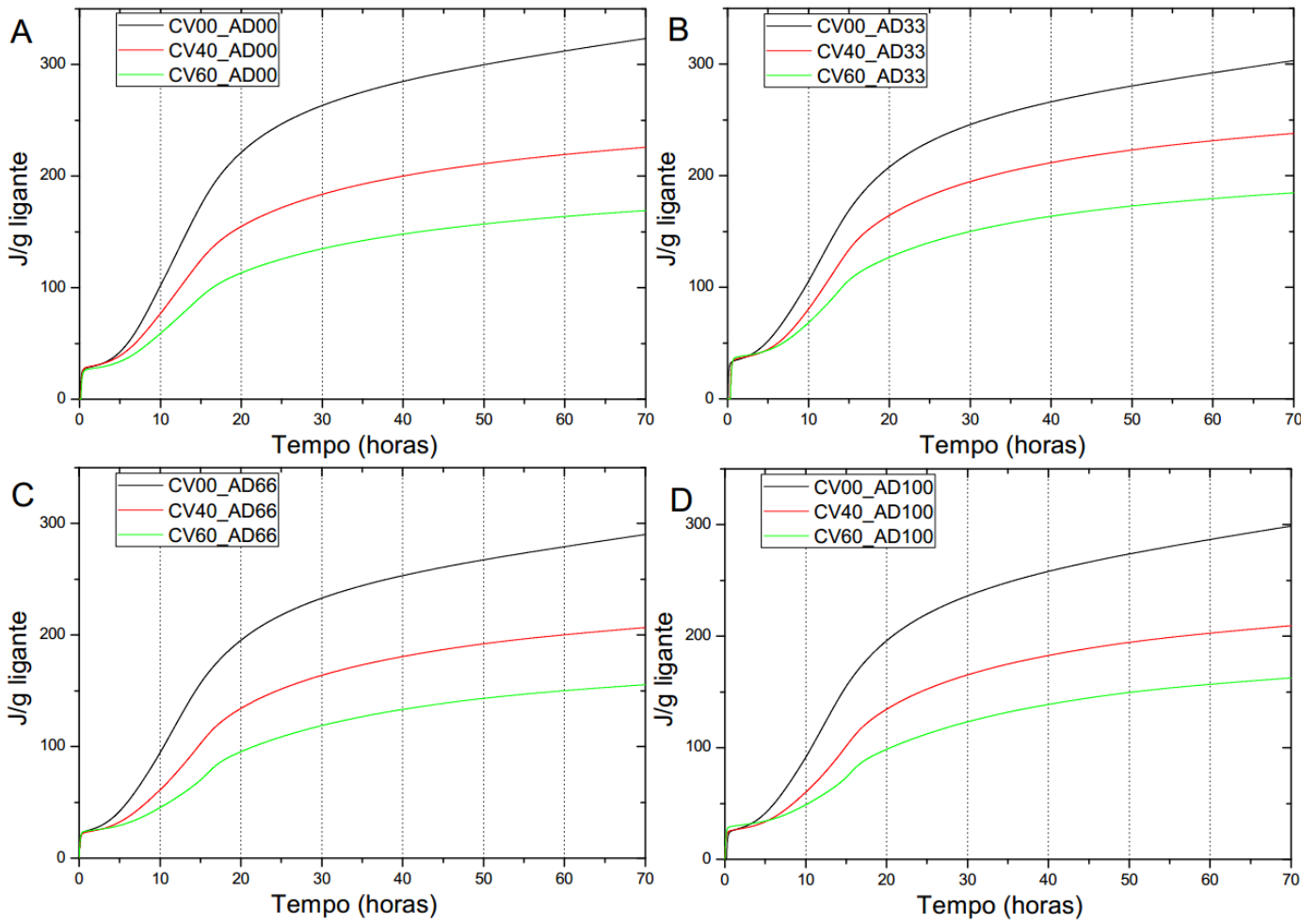

Figura 2: Calor acumulado durante 72 horas de hidratação. Sistemas com incorporação de aditivo nas proporções de: A. $0,00 \%$; B. $0,33 \%$; C. $0,66 \%$ e D. $1,00 \%$.

Com o intuito de se estimar o tempo de pega através do fluxo de calor da calorimetria isotérmica, traçou-se uma reta no tempo de hidratação correspondente à $50 \%$ do valor máximo do pico principal, seguindo as orientações da ASTM C1679 [38]. Os resultados podem ser observados na Tabela 5. O aditivo promoveu uma redução do tempo de pega final das amostras sem cinza volante em sua composição de cerca de 30 minutos. BOST, REGNIER, HORGNIES [39], por outro lado, observaram resultados mais expressivos com o uso do mesmo aditivo, com uma redução de cerca de 3,4 horas. Todavia, os resultados demonstraram um ligeiro aumento no tempo de pega das amostras compostas com $40 \%$ e $60 \%$ de cinza volante, tendo um aumento significativo na amostra com $60 \%$ de CV e $1 \%$ de aditivo. 
Tabela 5: Tempo de pega das diferentes amostras

\begin{tabular}{lccc}
\hline Designação & $\begin{array}{c}\text { Valor máximo do pico prin- } \\
\text { cipal (mW/g ligante) }\end{array}$ & $\begin{array}{c}\text { Tempo onde ocorre 50\% do valor } \\
\text { do pico principal (minutos) }\end{array}$ & $\begin{array}{c}\text { Tempo de fim de pega } \\
\text { estimado (horas) }\end{array}$ \\
\hline CV0_AD0 & 4,14 & 308 & 5,13 \\
CV0_AD33 & 3,71 & 266 & 4,43 \\
CV0_AD66 & 3,62 & 262 & 4,36 \\
CV0_AD100 & 3,67 & 278 & 4,63 \\
\hline CV40_AD0 & 2,71 & 305 & 5,08 \\
CV40_AD33 & 3,07 & 354 & 5,90 \\
CV40_AD66 & 2,53 & 331 & 5,51 \\
CV40_AD100 & 2,65 & 403 & 6,72 \\
\hline CV60_AD0 & 1,86 & 312 & 5,20 \\
CV60_AD33 & 2,34 & 376 & 6,27 \\
CV60_AD66 & 2,00 & 494 & 8,23 \\
CV60_AD100 & 2,17 & 595 & 9,92 \\
\hline
\end{tabular}

\section{2 Índice de consistência normal}

Na Tabela 6Tabela 6 são apresentados os valores médios de índice de consistência normal para cada uma das configurações analisadas. Constata-se que o aumento do teor de cinza volante acarretou um aumento no índice de consistência. A configuração CV0_AD0 apresentou um valor médio de $246,5 \mathrm{~mm}$, enquanto que a CV40_AD0 um valor de $256,5 \mathrm{~mm}$ e a CV60_AD0 um valor de $282,5 \mathrm{~mm}$, o que corresponde, respectivamente, a um aumento de $4 \%$ e $12 \%$ do índice de consistência. O mesmo comportamento foi verificado por outros pesquisadores, aonde a utilização de cinza volante em argamassas e concretos tem demonstrado uma melhoria significativa em propriedades como a trabalhabilidade [40] [41] [42]. As características da cinza volante que exercem grande influência nesta propriedade são a morfologia esférica, a superfície do material e a dimensão da partícula [9] [43]. Neste âmbito, LOTHENBACH et al. [44] destacam que a forma esférica das partículas da CV permitem uma maior trabalhabilidade para uma mesma relação de água/cimento.

Tabela 6: Índice de consistência normal (NBR 7215:1997 [27]) para todas as configurações analisadas

\begin{tabular}{ccc}
\hline Configuração & $\begin{array}{c}\text { Índice de consistência } \\
\text { médio }(\mathbf{m m})\end{array}$ & Desvio padrão (mm) \\
\hline CV0_AD0 & 246,50 & 2,12 \\
\hline CV40_AD0 & 256,50 & 9,19 \\
\hline CV60_AD0 & 282,50 & 0,71 \\
\hline CV0_AD33 & 194,00 & 2,83 \\
\hline CV40_AD33 & 249,50 & 0,71 \\
\hline CV60_AD33 & 300,50 & 0,71 \\
\hline CV0_AD66 & 201,00 & 1,41 \\
\hline CV40_AD66 & 287,00 & 4,24 \\
\hline CV60_AD66 & 308,50 & 4,95 \\
\hline CV0_AD100 & 235,00 & 0,00 \\
\hline CV40_AD100 & 298,50 & 2,12 \\
\hline CV60_AD100 & 309,50 & 3,54 \\
\hline
\end{tabular}

Também é possível verificar que para as argamassas sem adição de cinza volante (CV0_AD0, CV0_AD33, CV0_AD66, CV0_AD100) a utilização do aditivo provocou uma redução do índice de consistência, sendo o teor de aditivo de $0,33 \%$ o mais impactante, ocasionando um decréscimo de $21,3 \%$ em relação à configuração CV0_AD0. Para as argamassas com CV, foi verificada a tendência de aumento do índice de consistência com o aumento do teor de aditivo, com exceção do traço CV40_AD33, que apresentou uma redução de aproximadamente $5 \%$ em relação ao valor médio da configuração CV40_AD0. Para as configura- 
ções com teor de $40 \%$ de cinza volante, o teor de aditivo que promoveu o maior índice de consistência foi o de $1,00 \%$, com um aumento de 14,81\% em relação à referência (CV40_AD0). O mesmo foi constatado para as configurações com teor de $60 \%$ de $\mathrm{CV}$, sendo que o índice teve um acréscimo de $9,56 \%$ em relação à referência (CV60_AD0). Este comportamento é coerente com o identificado em outras pesquisas, aonde a incorporação de aditivos baseados em nitrato de cálcio em porcentagens inferiores a 1,00\% não afetou negativamente a trabalhabilidade das misturas [45].

Na Tabela 7 encontra-se a análise de variância aplicada ao estudo, com o intuito de verificar a influência dos fatores controláveis: teor de CV (A), teor de aditivo acelerador de resistência inicial (B) e a interação entre tais fatores na variável de resposta índice de consistência normal. De acordo com esta análise de variância e considerando um nível de significância de 5\% como critério de decisão, constatou-se que o teor de CV, o teor de aditivo e a interação entre ambos exercem influência significativa no índice de consistência.

Tabela 7: Análise de variância (ANOVA) do índice de consistência normal

\begin{tabular}{lcccccc}
\hline \multicolumn{1}{c}{ Fonte } & SQ & GDL & MQ & Teste F & Probabilidade & Comentário \\
\hline Teor de CV (A) & 27252,583 & 2,000 & 13626,292 & 1021,972 & $0,0000000000040 \%$ & $\mathrm{~S}$ \\
Teor de aditivo (B) & 3311,500 & 3,000 & 1103,833 & 82,788 & $0,0000027549760 \%$ & $\mathrm{~S}$ \\
$\mathrm{AB}$ & 4889,750 & 6,000 & 814,958 & 61,122 & $0,0000026813285 \%$ & $\mathrm{~S}$ \\
Erro & 160,000 & 12,000 & 13,333 & & & \\
\hline \multicolumn{2}{c}{ Total } & 35613,833 & 23 & & & \\
\hline
\end{tabular}

* S - Significativo, NS - Não significativo

Também foi realizada a comparação de média entre os diferentes níveis de teor de aditivo. Assim, para as configurações sem CV e com $40 \%$ de CV, constatou-se que existem diferenças estatísticas significativas entre os quatro teores de aditivo e que o teor ótimo para ambos os casos é de $1 \%$, visto que, para o primeiro caso, foi o teor que gerou a menor redução do índice de consistência em relação à argamassa de referências (CV0_AD0) e, para o segundo caso, aquele que gerou a melhor trabalhabilidade. Por fim, para as argamassas com $60 \%$ de CV verificou-se que não existem diferenças significativas entre o teor de $0,66 \%$ e $1 \%$. Desta forma, conclui-se que para este caso o teor de aditivo ótimo é o de $0,66 \%$, uma vez que a concentração de $1 \%$ não alterou significativamente a variável de resposta.

\subsection{Resistência à compressão uniaxial}

As Figura 3, 4 e 5 apresentam os resultados obtidos no ensaio de resistência à compressão das amostras para os variados teores de aditivo pré-estabelecidos. A análise dos resultados alcançados permite inferir que para as argamassas sem CV houve um incremento da resistência à compressão no primeiro dia em, aproximadamente, $20 \%$ em relação à argamassa de referência, com o emprego de 1,00\% de aditivo, conforme ilustrado pela Figura 4. Diversas pesquisas evidenciam que o aditivo à base de nitrato de cálcio afeta, positivamente, a evolução da resistência à compressão na idade inicial comparado com o sistema de referência [13]. Para MEAGHER et al. [11], esse aumento da resistência à compressão na idade inicial das amostras é esperado, pois o aditivo à base de nitrato de cálcio acelera a hidratação do $\mathrm{C}_{3} \mathrm{~S}$ do cimento, que depende da taxa de concentração de cálcio em solução para iniciar a formação do silicato de cálcio hidratado (C-S-H), principal produto de hidratação do cimento Portland e responsável pelas suas propriedades mecânicas. Entretanto, não há uma indicação de tendência quanto ao acréscimo das resistências mecânicas para as demais idades, pois foram observadas reduções de aproximadamente $8 \%$ para as idades de 3 e 7 dias e de $12 \%$ aos 28 dias, comparados ao traço de referência CV0_AD0. Neste sentido existe certa controvérsia devido a resultados que apresentam um aumento da resistência a longo prazo em sistemas com a presença de aditivos aceleradores a base de nitrato de cálcio [46][47][48], assim como a redução do comportamento mecânico por efeito dos aceleradores [49]. Contudo, para AÏTCIN [7] a aceleração de hidratação do $\mathrm{C}_{3} \mathrm{~S}$ pode ter efeitos secundários negativos, reduzindo as resistências à longo prazo e a durabilidade do concreto. 


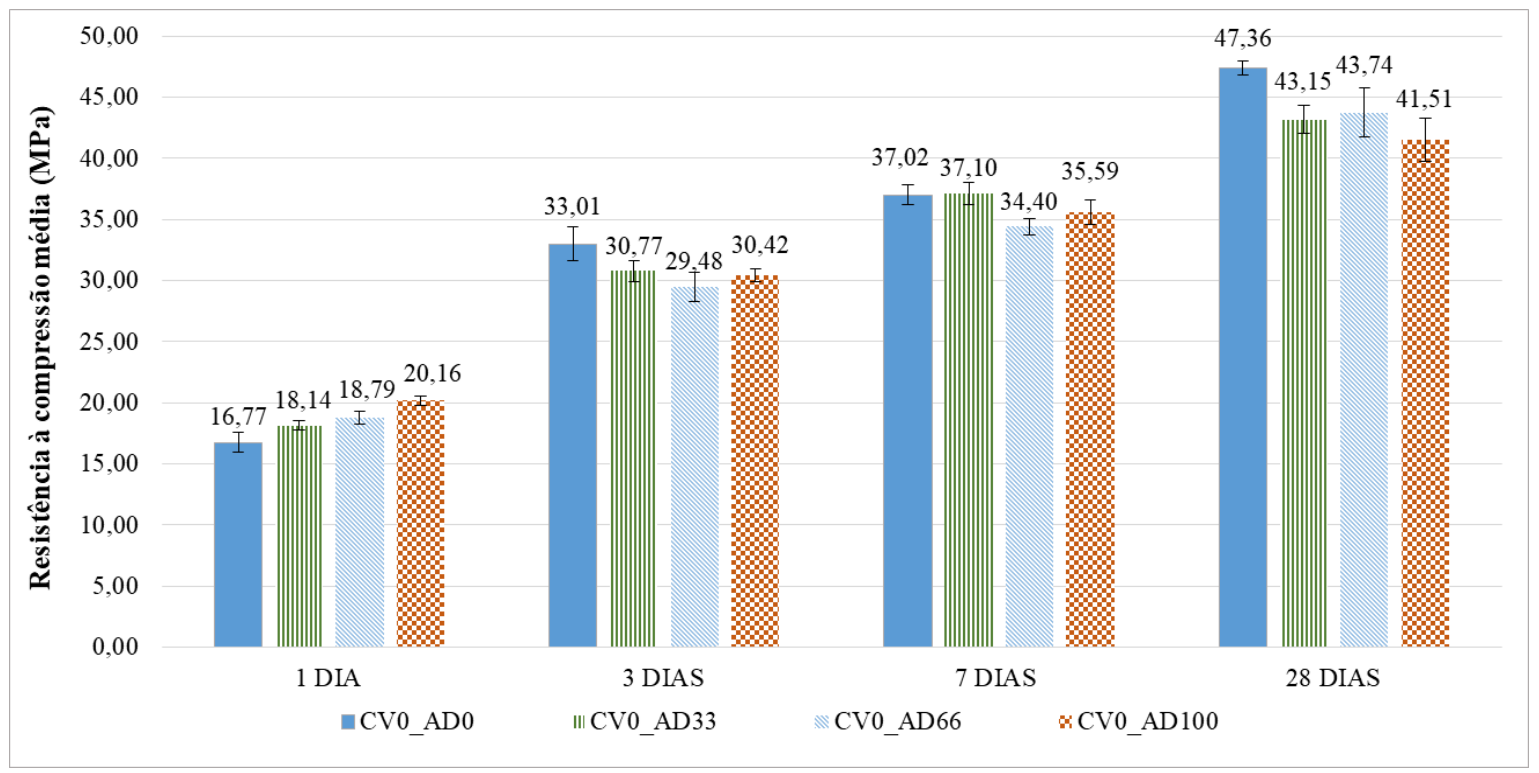

Figura 3: Resistência à compressão das argamassas de cimento Portland CP V com diferentes idades de cura e variando o teor de aditivo

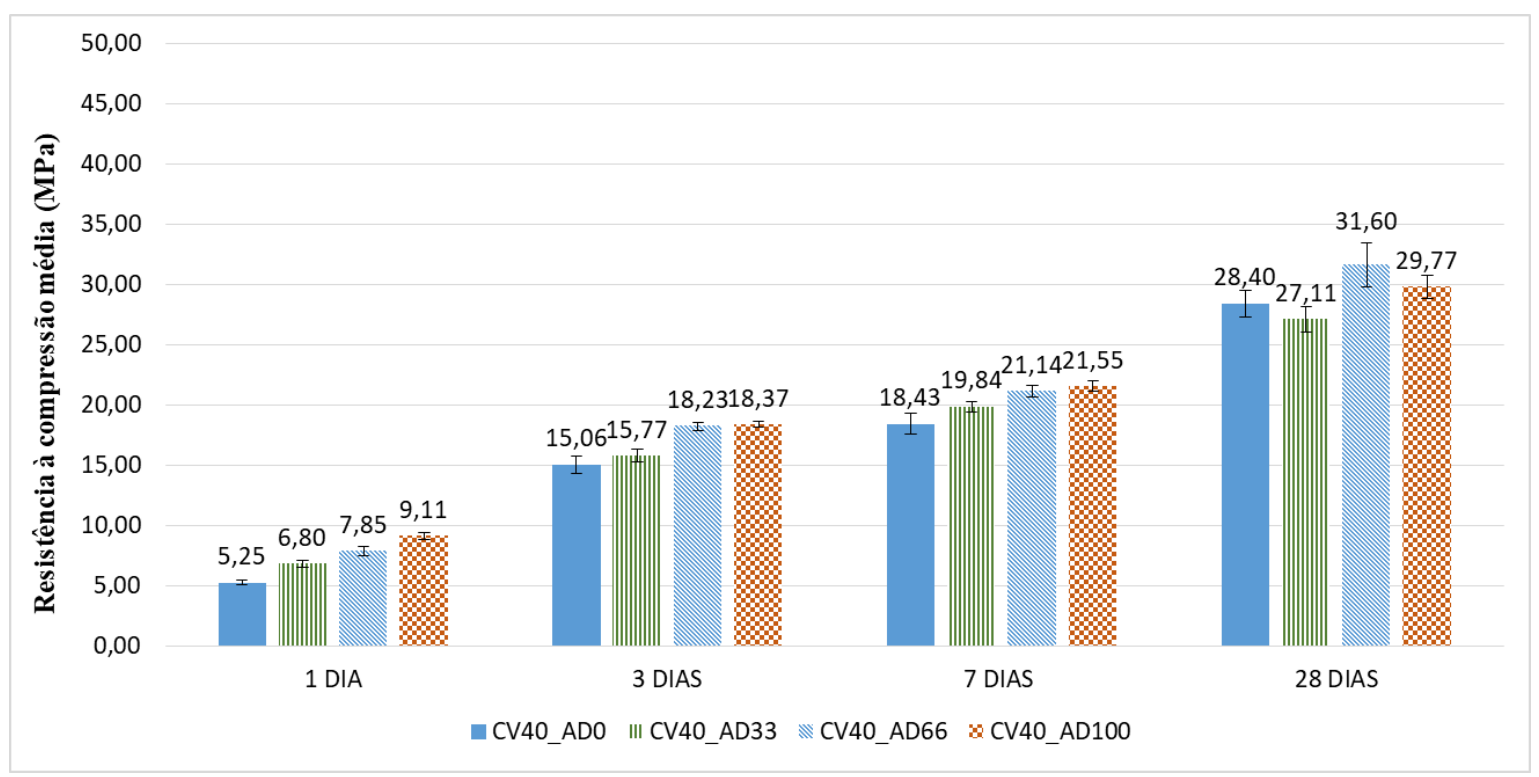

Figura 4: Resistência à compressão das argamassas com $40 \%$ de substituição de cimento CP V por cinza volante variando o teor de aditivo 


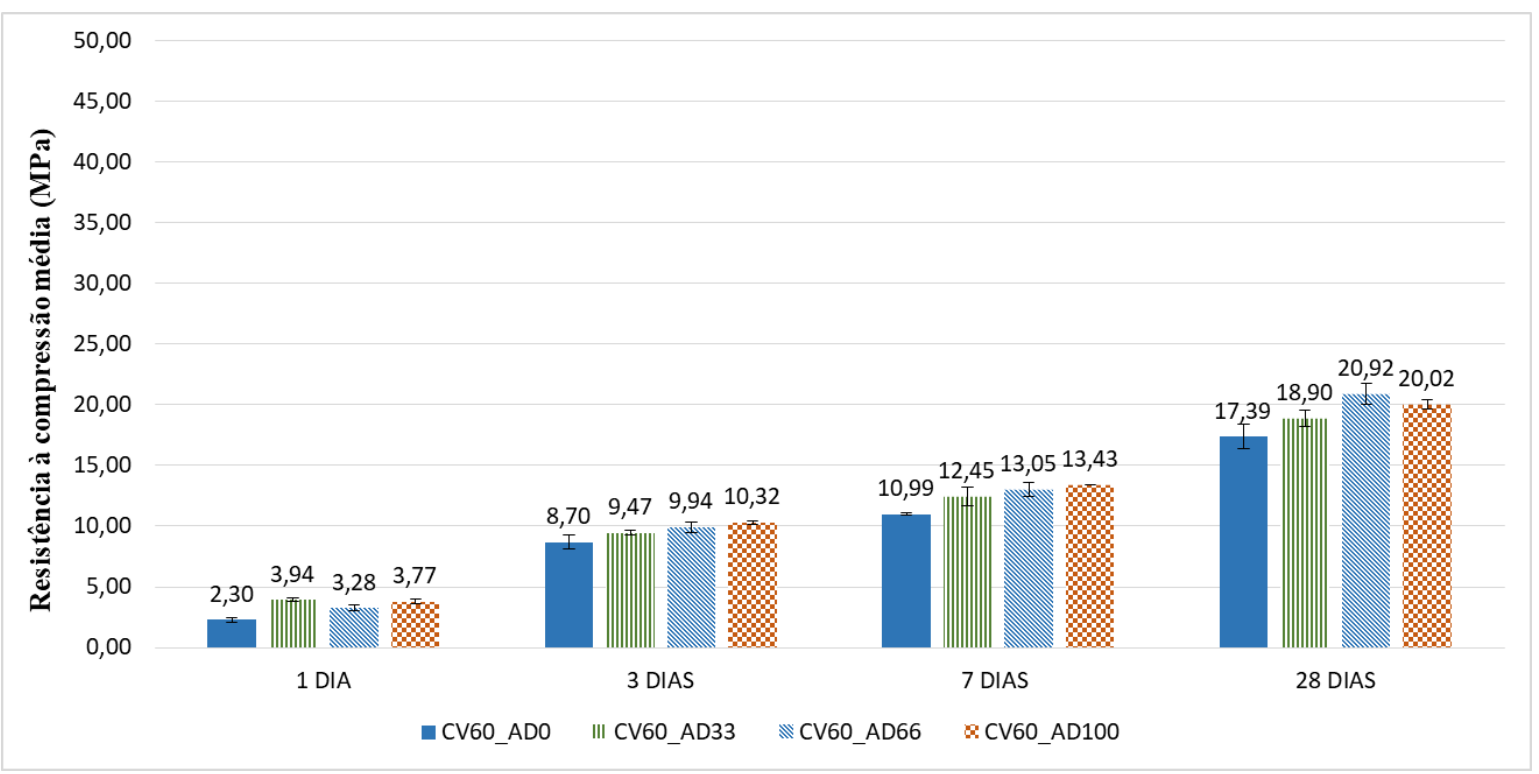

Figura 5: Resistência à compressão das argamassas com $60 \%$ de substituição de cimento CPV por cinza volante variando o teor de aditivo

O uso de aditivo na confecção das amostras com 40 e $60 \%$ de substituição do cimento por cinza volante (Figuras 4 e 5 respectivamente) resultou em uma tendência de aumento nos valores referentes à resistência à compressão. Para o traço CV40_AD100 foi observado um acréscimo de $23 \%$ no primeiro dia e $10 \%$ na idade de 3 dias, conforme Figura 4. Já para a amostra CV60_AD100, estes valores foram de 9\% e 5\%, respectivamente, como é evidenciado na Figura 5. De acordo com SOUNTHARARAJAN et al. [50], a substituição de cimento Portland por CV retarda o ganho de resistência inicial de concreto e argamassas. Desta forma, os aditivos aceleradores de resistência vêm sendo utilizados com o intuito de garantir um resultado mais satisfatório nas primeiras idades para sistemas com uma reatividade menor. Tais resultados foram similares no trabalho de HILL et al. [51], evidenciando o possível efeito do aditivo a base de nitrato de cálcio nas reações de hidratação do cimento com adição de CV [51] [52]. As amostras com substituição de cimento por cinza volante apresentaram, até a idade de 7 dias, melhores resultados para os traços com teor de $1 \%$ de aditivo. Entretanto, com relação à resistência aos 28 dias, apesar dos valores ainda superiores, o traço de argamassa que teve melhores resultados foi aquele com teor de aditivo de $0,66 \%$.

Na Tabela 8 encontra-se a análise de variância aplicada ao estudo, com o intuito de verificar a influência dos fatores controláveis: cinza volante $(\mathrm{A})$, teor de aditivo $(\mathrm{B})$ e idade $(\mathrm{C})$, na resistência à compressão de argamassas. De acordo com a análise de variância obtida na avaliação da resistência à compressão das argamassas analisadas, constatou-se que todos os fatores, bem como suas interações exercem influência significativa na variável de resposta, considerando um nível de confiança de $95 \%$.

Tabela 8: Análise de variância (ANOVA) dos resultados de resistência à compressão

\begin{tabular}{ccccccc}
\hline Fonte & SQ & GDL & MQ & Teste F & Probabilidade & Comentário \\
\hline Cinza volante (A) & 11103,991 & 2 & 5551,996 & 3338,383 & $0,00000000 \%$ & $\mathrm{~S}$ \\
Aditivo (B) & 26,646 & 3 & 8,882 & 5,341 & $0,29538170 \%$ & $\mathrm{~S}$ \\
Idade (C) & 8355,811 & 3 & 2785,270 & 1674,767 & $0,00000000 \%$ & $\mathrm{~S}$ \\
AB & 111,933 & 6 & 18,656 & 11,217 & $0,00000860 \%$ & $\mathrm{~S}$ \\
AC & 339,354 & 6 & 56,559 & 34,009 & $0,00000000 \%$ & $\mathrm{~S}$ \\
BC & 48,510 & 9 & 5,390 & 3,241 & $0,37713633 \%$ & $\mathrm{~S}$ \\
ABC & 63,861 & 18 & 3,548 & 2,133 & $1,89329667 \%$ & \\
Erro & 79,828 & 48 & 1,663 & & & \\
\hline Total & 20129,934 & 95 & & & & \\
\hline
\end{tabular}

* S - Significativo, NS - Não significativo 
Analisando a influência da CV na resistência à compressão para diferentes idades, os resultados encontrados foram estatisticamente diferentes, conforme já era esperado, devido ao caráter pozolânico das cinzas volantes. Entretanto, percebe-se que ao se utilizar o aditivo de nitrato de cálcio houve aumento nos valores referentes à resistência à compressão na idade de 1 dia. Para as argamassas com $0 \%$ e $40 \%$ de CV o teor que gerou o maior valor de resistência à compressão foi o de $1 \%$. Já para as argamassas com $60 \%$ de CV, os quatro teores de aditivo são estatisticamente iguais. Para as demais idades, de maneira geral, o aditivo ocasionou uma redução da resistência à compressão nas amostras sem CV. Já para as amostras com $40 \%$ e $60 \%$ de $\mathrm{CV}$ houve um aumento da resistência proporcional ao teor de aditivo.

\subsection{Absorção de água por capilaridade}

Analisando a Figura 6 é possível verificar a influência do teor de CV quando se mantém constante o teor de aditivo. O acréscimo do teor de cinza ocasionou uma tendência de aumento do índice de absorção de água por capilaridade, propriedade que está diretamente relacionada à porosidade da matriz cimentícia.

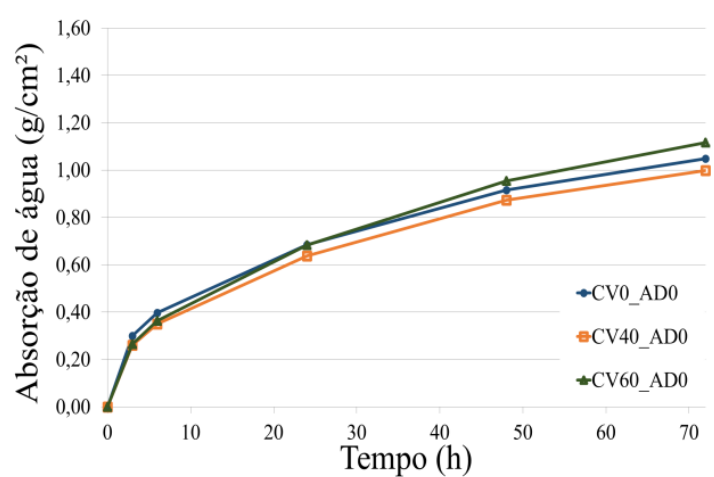

a) Índice de absorção para os traços sem aditivos

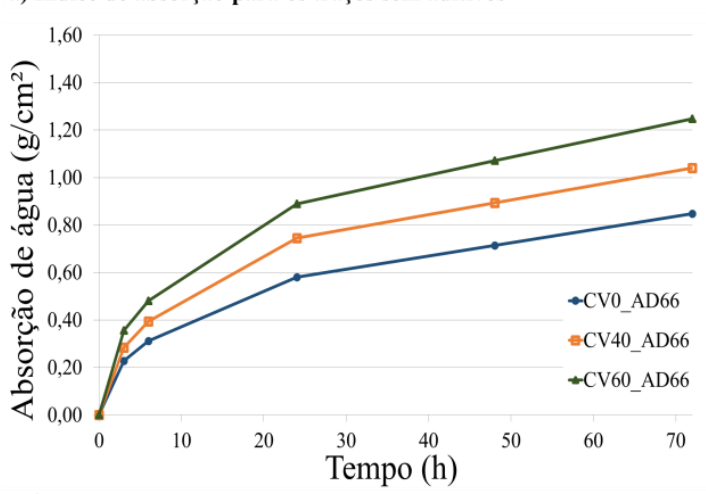

c) Índice de absorção para os traços com teor de $0,66 \%$ de aditivo

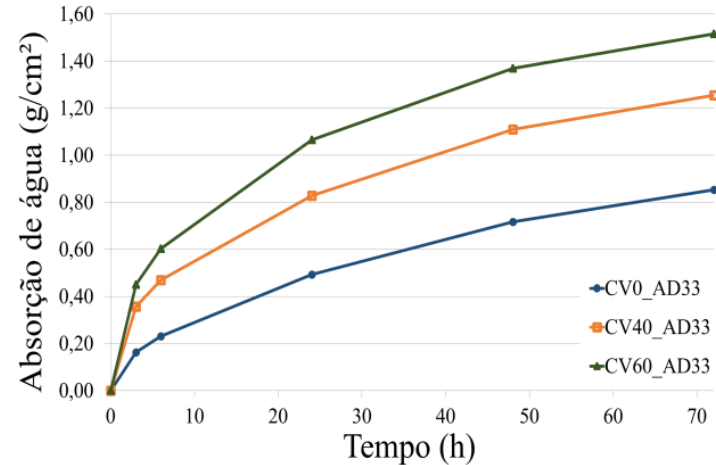

b) Índice de absorção para os traços com teor de $\mathbf{0 , 3 3} \%$ de aditivo

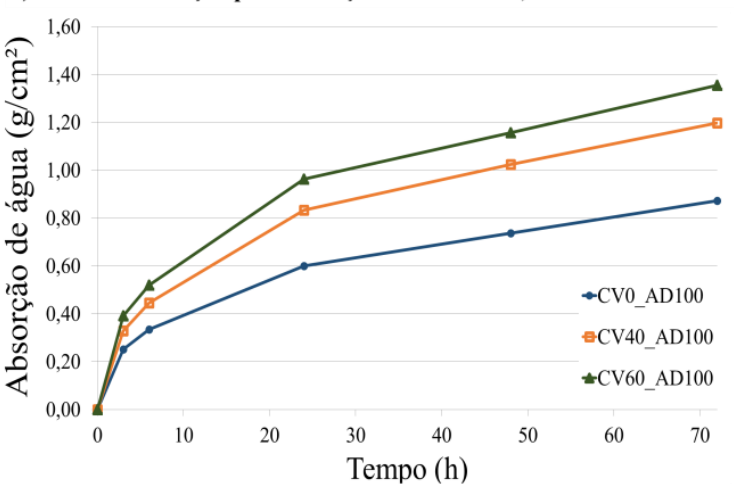

d) Índice de absorção para os traços com teor de $1 \%$ de aditivo

Figura 6: Influência dos teores de cinza volante no índice de absorção para os traços com: a) sem aditivo, b) com 0,33\% de aditivo, c) com $0,66 \%$ de aditivo e d) com $1 \%$ de aditivo em argamassas com 28 dias de cura.

Considerando que o ensaio de absorção foi realizado com corpos de prova com 28 dias de idade, destaca-se o fato de que as misturas com CV apresentaram, para esta idade, porosidade maior, o que pode ser explicado pelo fato de que aos 28 dias nem todas as reações pozolânicas se completaram e não reduziram a porosidade da matriz cimentícia como era o esperado em idades mais avançadas. Outro aspecto que deve ser levado em consideração para explicar tal comportamento é o elevado teor de substituição de cimento Portland por CV. Para um teor de substituição de $60 \%$ de CV, possivelmente não existirá Portlandita disponível para reagir com todo o material pozolânico adicionado, o que contribuiu para os maiores índices de absorção de água por capilaridade.

Em relação a influência do teor de aditivo no índice de absorção por capilaridade, nos corpos de prova sem adição de cinza volante, o aumento da proporção de aditivo resultou em uma diminuição dos índices de absorção. Todavia, nas amostras com cinza volante, os menores índices de absorção foram obtidos para os traços que não possuíam aditivo, sendo que em ambos os casos, com substituição de $40 \%$ e $60 \%$ da massa do cimento por cinza, não houve uma relação direta entre o aumento de aditivo e o aumento da absorção. $O$ teor de aditivo que apresentou os maiores índices de absorção foi o de $0,33 \%$. 
Na Tabela 9 encontra-se a análise de variância aplicada ao estudo, com o intuito de verificar a influência dos fatores controláveis: teor de cinza volante (A), teor de aditivo acelerador de resistência inicial (B), tempo (C) e a interação entre tais fatores na variável de resposta índice de absorção por capilaridade. De acordo com esta análise de variância e considerando um nível de significância de 5\% como critério de decisão, constatou-se que o teor de $\mathrm{CV}$, o teor de aditivo, o tempo e a interações $\mathrm{AB}$ e $\mathrm{AC}$ exercem influência significativa no índice de absorção por capilaridade, sendo as interações de segunda ordem, teor de aditivo e tempo e a interação de terceira ordem, teor de $\mathrm{CV}$, aditivo e tempo não significativas.

Tabela 9: Análise de variância (ANOVA) dos resultados obtidos no ensaio de absorção por capilaridade

\begin{tabular}{|c|c|c|c|c|c|c|}
\hline Fonte & SQ & GDL & MQ & Teste F & Probabilidade & Comentário* \\
\hline Teor de CV (A) & 2,301 & 2 & 1,151 & 68,907 & $0,000000000000000001 \%$ & $\mathrm{~S}$ \\
\hline Teor de aditivo (B) & 0,356 & 3 & 0,119 & 7,111 & $0,019446159869470800 \%$ & $S$ \\
\hline Tempo (C) & 17,402 & 4 & 4,351 & 260,557 & $0,000000000000000000 \%$ & $S$ \\
\hline $\mathrm{AB}$ & 1,037 & 6 & 0,173 & 10,346 & $0,000000319913042319 \%$ & $S$ \\
\hline $\mathrm{AC}$ & 0,347 & 8 & 0,043 & 2,597 & $1,182853577743320000 \%$ & $S$ \\
\hline $\mathrm{BC}$ & 0,111 & 12 & 0,009 & 0,552 & $87,613992514056300000 \%$ & NS \\
\hline $\mathrm{ABC}$ & 0,074 & 24 & 0,003 & 0,184 & $99,999259140764000000 \%$ & NS \\
\hline Erro & 2,004 & 120 & 0,017 & & & \\
\hline Total & 23,631 & 179 & & & & \\
\hline
\end{tabular}

* S - Significativo, NS - Não significativo

Também foi realizada a comparação de médias entre os diferentes níveis de teor de aditivo, considerando o índice de absorção final (72 horas). Para as configurações sem CV, os teores de aditivo de $0,33 \%$, $0,66 \%$ e $1 \%$ mostraram-se estatisticamente iguais. Desta forma, conclui-se que o teor ótimo é o de $0,33 \%$, visto que é a concentração mais econômica. Para as argamassas com $40 \%$ e $60 \%$ de CV o teor de aditivo que gerou os menores índices de absorção é o de $0,66 \%$.

\section{CONCLUSÕES}

Esta pesquisa avaliou a influência de um aditivo acelerador de resistência inicial baseado em nitrato de cálcio em algumas propriedades de argamassas de cimento Portland com teores de substituição de CV de 0\%, 40\% e $60 \%$. Os resultados encontrados indicam que:

- Em relação à calorimetria, detectou-se uma redução do fluxo de calor inicial, nas concentrações de aditivo de $0,66 \%$ e $1,00 \%$ para os três teores de CV. Diante disso, é possível concluir que a utilização do aditivo se mostra mais adequada às estruturas em que existe a problemática do calor excessivo produzido pelas reações químicas da hidratação e ao mesmo tempo existe a necessidade de ganho de resistência em idades iniciais. No que se refere ao tempo de pega final, nas amostras que não possuíam cinza volante em sua composição, o aditivo aparentou acelerar este período (em até 30 minutos). Contudo, para as amostras com $40 \%$ verificou-se um ligeiro aumento no tempo de pega e, para as pastas com $60 \%$ de CV um aumento significativo proporcional ao teor de aditivo.

- Em relação ao índice de consistência verificou-se que, para as argamassas sem CV, o aditivo promoveu uma redução do índice de consistência, sendo que, para esta propriedade, o teor que apresentou o melhor resultado foi o de 1,00\%, visto que foi o que menos impactou na trabalhabilidade. Já para as argamassas com CV observou-se uma tendência de aumento do índice de consistência com o aumento do teor de aditivo; para as argamassas com $40 \%$ de $\mathrm{CV}$ o teor ótimo foi de 1,00\% e para as argamassas com $60 \%$ de CV de $0,66 \%$.

- Para as resistências à compressão na idade de 1 dia, o teor de aditivo que gerou os maiores valores foi o de $1 \%$ para as argamassas com $0 \%$ e $40 \% \mathrm{CV}$, não existindo diferenças estatisticamente significativas para as misturas com $60 \%$. Já para as resistências em idades superiores, o aditivo ocasionou reduções na resistência à compressão nas amostras sem CV e aumentos proporcionais ao teor de aditivo para as amostras com $40 \%$ e $60 \%$ de CV. Por fim, com base nos resultados previamente apresentados, conclui-se que houve um aumento das resistências iniciais devido à incorporação do aditivo, mas que este acréscimo não foi suficiente para compensar a queda de resistência nas primeiras idades pela incorporação de CV na composição das amostras. 
- Constatou-se que nas argamassas sem CV o aditivo gerou uma redução no índice de absorção por capilaridade. Entretanto para as amostras com $40 \%$ e $60 \%$ de substituição de $\mathrm{CV}$, não foi verificada uma relação direta entre o aumento do teor do aditivo e o aumento da absorção. Para estes casos, os menores índices de absorção foram obtidos para os traços sem aditivo.

A partir dos ensaios realizados observou-se não ser possível estabelecer um teor ótimo de aditivo para cada teor de CV estabelecido, levando em consideração as diferentes propriedades avaliadas. Obtiveram-se proporções ótimas de aditivos diferentes para cada uma delas. Sendo necessário avaliar qual propriedade é de maior interesse ao usuário.

\section{AGRADECIMENTOS}

Os autores agradecem ao Conselho Nacional de Desenvolvimento Científico e Tecnológico (CNPq), à FAPEMA (Fundação de Amparo à Pesquisa e ao Desenvolvimento Científico e Tecnológico do Maranhão) e ao Laboratório de Materiais Cerâmicos (LACER/UFRGS) por tornarem este estudo possível.

\section{BIBLIOGRAFIA}

[1] AHMAD, H., CAROLINA, N., SCHEMMEL, J. J., ELLIOTT, R. P., "Mechanical Behavior of High Early Strength Concrete", Strategic Highway Research Program, v. 4, 1993.

[2] ASSOCIAÇÃO BRASILEIRA DE NORMAS TÉCNICAS, NBR 11768: Aditivos químicos para concreto de cimento Portland - Requisitos, Rio de Janeiro, 2011.

[3] AMERICAN SOCIETY FOR TESTING AND MATERIALS, ASTM C-494: Standard Specification for Chemical Admixtures for Concrete, USA, 2017.

[4] HARTMANN, C., JEKNAVORIAN, A., SILVA, D., BENINI, H., "Aditivos químicos para concreto e cimento”, In: Isaia, G. C. (ed), Concreto: Ciência e tecnologia, São Paulo, pp. 347-380, 2011.

[5] EDMEADES, R. M., HEWLETT, P. C., “Cement Admixtures”, In: Hewlett, P. C. (ed), Lea's Chemistry of Cement and Concrete, Elsevier Science \& Technology Books, 4th ed., pp. 841-905, 2004.

[6] SALVADOR, R. P., CAVALARO, S. H. P., SEGURA, I., et al., "Early age hydration of cement pastes with different types of accelerators for sprayed concrete", Construction and Building Materials, v.111, pp. 129, 2016.

[7] AÏTCIN, P. C., “Accelerators”, In: AÏTCIN, R. J., FLATT, P. C., (eds.), Science and Technology of Concrete Admixtures, Elsevier, 1st ed., pp. 405-413, 2016.

[8] NEVILLE, A. M, Propriedades do Concreto, Bookman, 5th ed., Porto Alegre, 2015.

[9] MEHTA, P. K., MONTEIRO, P. J., Concrete: Microstructures, Properties, and Materials, McGraw-Hill, 2014.

[10] RIXOM, R., "The economic aspects of admixture use", Cement and Concrete Composites, v.20, n.2-3, pp. 141-147, 1998.

[11] MEAGHER, T., SHANAHAN, N., BUIDENS, D., et al., "Effects of chloride and chloride-free accelerators combined with typical admixtures on the early-age cracking risk of concrete repair slabs", Construction and Building Materials, v.94, pp. 270-279, 2015.

[12] RIXOM, R., MAILVAGANAM, N., Chemical Admixtures for Concrete, E \& FN Spon, 3rd ed., London, 1999.

[13] AGGOUN, S., CHEIKH-ZOUAOUI, M., CHIKH, N., DUVAL, R., "Effect of some admixtures on the setting time and strength evolution of cement pastes at early ages", Construction and Building Materials, 22(2), pp. 106-110, 2008.

[14] HOANG, K., JUSTNES, H., GEIKER, M., "Early age strength increase of fly ash blended cement by a ternary hardening accelerating admixture", Cement and Concrete Research, v.81, pp. 59-69, 2016.

[15] AMERICAN CONCRETE INSTITUTE, Manual of Concrete Practice, Farmington Hills, 2016.

[16] JUSTNES, H., NYGAARD, E. C., "Technical calcium nitrate as set accelerator for cement at low temperatures", Cement and Concrete Research, v. 25, n. 8, pp. 1766-1774, 1995.

[17] JUSTNES, H., PETERSEN, B., "Counteracting Plasticizer Retardation of Cement Setting with Calcium Nitrate", In: Int. Conf. Innovations and Developments in Concrete Materials and Construction, 9, pp. 259$267,2002$. 
[18] KARAGÖL, F., DEMIRBOĞA, R., KAYGUSUZ, M. A., et al., "The influence of calcium nitrate as anti-freeze admixture on the compressive strength of concrete exposed to low temperatures", Cold Regions Science and Technology, v.89, pp. 30-35, 2013.

[19] JUSTNES, H., "Corrosion Inhibitors for concrete", IN: International Symposium on Durability of Concrete I Memory of Prof. Dr. Raymundo, Rivera, pp. 179-199, 2005.

[20] LOTHENBACH, B., SCRIVENER, K., HOOTON, R. D., "Supplementary cementitious materials", Cement and Concrete Research, v.41, n.12, pp. 1244-1256, 2011.

[21] ASSOCIAÇÃO BRASILEIRA DE NORMAS TÉCNICAS, NBR 5733: Cimento Portland de alta resistência inicial, Rio de Janeiro, 1991.

[22] ASSOCIAÇÃO BRASILEIRA DE NORMAS TÉCNICAS, NBR NM 23: Cimento Portland e outros materiais em pó - Determinação da massa específica, Rio de Janeiro, 2001.

[23] ASSOCIAÇAO BRASILEIRA DE NORMAS TÉCNICAS, NBR NM 18: Cimento Portland - Análise química - Determinação da perda ao fogo, Rio de Janeiro, 2012.

[24] ASSOCIAÇÃO BRASILEIRA DE NORMAS TÉCNICAS, NBR 16372: Cimento Portland e outros materiais em pó - Determinação da finura pelo método de permeabilidade ao ar (método Blaine), Rio de Janeiro, 2015.

[25] ASSOCIAÇÃO BRASILEIRA DE NORMAS TÉCNICAS, NBR 11582: Cimento Portland - Determinação da expansibilidade de Le Chatelier, Rio de Janeiro, 2016.

[26] ASSOCIAÇÃO BRASILEIRA DE NORMAS TÉCNICAS, NBR NM 65: Cimento Portland - Determinação do tempo de pega, Rio de Janeiro, 2003.

[27] ASSOCIAÇÃO BRASILEIRA DE NORMAS TÉCNICAS, NBR 7215: Cimento Portland - Determinação da Resistência à Compressão, Rio de Janeiro, 1997.

[28] ASSOCIAÇÃO BRASILEIRA DE NORMAS TÉCNICAS, NBR 7214: Areia normal para ensaio de cimento - Especificação, Rio de Janeiro, 2015.

[29] ASSOCIAÇÃO BRASILEIRA DE NORMAS TÉCNICAS, NBR NM 248: Agregados - Determinação da composição granulométrica, Rio de Janeiro, 2003.

[30] ASSOCIAÇÃO BRASILEIRA DE NORMAS TÉCNICAS, NBR NM 52: Agregado miúdo - Determinação da massa específica e massa específica aparente, Rio de Janeiro, 2009.

[31] ASSOCIAÇÃO BRASILEIRA DE NORMAS TÉCNICAS, NBR NM 45: Agregados - Determinação da massa unitária e do volume de vazios, Rio de Janeiro, 2006.

[32] ASSOCIAÇÃO BRASILEIRA DE NORMAS TÉCNICAS, NBR NM 30: Agregado Miúdo - Determinação da absorção de água, Rio de Janeiro, 2001.

[33] ASSOCIAÇÃO BRASILEIRA DE NORMAS TÉCNICAS, NBR 9779: Argamassas e concretos endurecidos - Determinação da absorção por capilaridade, Rio de Janeiro, 2012.

[34] KIM, S. G., WANG, K., Effect of heat generation from cement hydration on mass concrete placement, Tese de D.Sc., Iowa State University, Iowa, 2010.

[35] GARTNER, E. M., YOUNG, J. F., DAMIDOT, A. A., et al., "Hydration of Portland Cement", In: Bensted, J., Barnes, P. (eds), Structure and Performance of Cements, 2nd ed, pp. 57-113, CRC Press, 2001.

[36] OEY, T., STOIAN, J., LI, J., et al., "Comparison of $\mathrm{Ca}(\mathrm{NO} 3) 2$ and $\mathrm{CaCl} 2$ admixtures on reaction, setting and strength evolutions in plain and blended cementing formulations", J. Mater. Civ. Eng., v. 27, n. 3, pp. 1-12, 2010.

[37] NOCÚN-WCZELIK, W., "Differential calorimetry as a tool in the studies of cement hydration kinetics with sulphate and nitrate solutions", J. Therm. Anal. Calorim., v. 130, n. 1, pp. 249-259, 2017.

[38] AMERICAN SOCIETY FOR TESTING AND MATERIALS, ASTM C1679: Standard Practice for Measuring Hydration Kinetics of Hydraulic Cementitious Mixtures Using Isothermal Calorimetry, West Conshohocken, PA, USA, 2014.

[39] BOST, P., REGNIER, M., HORGNIES, M., "Comparison of the accelerating effect of various additions on the early hydration of Portland cement", Constr. Build. Mater., v. 113, pp. 290-296, 2016.

[40] BENDAPUDI, S. C. K., SAHA, P., "Contribution of Fly Ash to the properties of mortar and concrete", International Journal of Earth Sciences and Engineering, v.4, pp. 1017-1022, 2011. 
[41] CHANDRA, L., HARDJITO, D., "The impact of using fly ash, silica fume and calcium carbonate on the workability and compressive strength of mortar", In: 5th International Conference of Euro Asia Civil Engineering Forum (EACEF-5), 125, pp. 773-779, 2015.

[42] NAGARATNAM, B. H., RAHMAN, M. E., MIRASA, A. K., et al., "Workability and heat of hydration of self-compacting concrete incorporating agro-industrial waste", Journal of Cleaner Production, v.112, pp. 882-894, 2016.

[43] DHIR, R. F., HUBBARD, F. H., MUNDAY, J. G. L., et al., "Contribution of PFA to concrete workability and strength development”, Cement and Concrete Research, v.18, pp. 277-289, 1988.

[44] LOTHENBACH, B., SCRIVENER, K., HOOTON, R. D., "Supplementary Cementing Materials", $C e$ ment and Concrete Research, 41, 2011.

[45] SKRIPKIŪNAS, G., KIČAITE், A., MACIJAUSKAS, M., "The influence of calcium nitrate on the plasticizing effect of cement paste", J. Civ. Eng. Manag., v. 22, n. 3, pp. 434-441, 2016.

[46] GÖK, S. G., KILINÇ, K., "Effect of calcium nitrate, triethanolamine and triisopropanolamine on compressive strength of mortars", University Journal of Engineering and Science, v.1, pp. 12-19, 2015.

[47] JUSTNES, H., THYS, A., VANPARIJS, F., et al., "Porosity and diffusivity of concrete with long-term compressive strength increase due to addition of the set accelerator calcium nitrate", In: 9th International Conference on Durability of Building Materials and Components, pp. 1-10, 2002.

[48] PRUDÊNCIO, L. R., "Accelerating admixtures for shotcrete”, Cement and Concrete Composites, v.20, n.2, pp. 213-219, 1998.

[49] PIZOŃ, J., "Long-term Compressive Strength of Mortars Modified with Hardening Accelerating Admixtures", Procedia Eng., v. 195, pp. 205-211, 2017.

[50] SOUNTHARARAJAN, V. M., SIVAKUMAR, A., "Effect of calcium nitrate on the pozzolanic properties of high early strength concrete”, Research Journal of Applied Sciences, Engineering and Technology, v.6, n.13, pp. 2502-2508, 2013.

[51] HILL, R. L., The study of hydration of fly ash in the presence of calcium nitrate and calcium formate, Tese de D.Sc, University of North Texas, 264 pp., may, 1994.

[52] SOUNTHARARAJAN, V. M., SIVAKUMAR, A., "The Effect of Accelerators and Mix Constituents on the High Early Strength Concrete Properties”, ISRN Civil Engineering, pp. 1-7, 2012. 